\title{
Correction to: Retinal complications of gout: a case report and review of the literature
}

Ying Jiang ${ }^{1}$, Jason E. Brenner ${ }^{1}$ and William J. Foster ${ }^{1,2^{*}}$

After publication of the article [1], it has been brought to our attention that the images displayed in Figs. 1, 2 and 3 have been transposed. Figure 1 should show the image from Fig. 2. Figure 2 should show the image from Fig. 3. Figure 3 should show the image from Fig. 1. The original article has now been revised to reflect this.

Received: 24 January 2018 Accepted: 24 January 2018

Published online: 05 February 2018

\section{Reference}

1. Jiang Y, Brenner J, Foster W. Retinal complications of gout: a case report and review of the literature. BMC Ophthalmol. 2018;18:1. https://doi.org/10. 1186/s12886-018-0669-6.

\footnotetext{
* Correspondence: tue84252@temple.edu

${ }^{1}$ Department of Ophthalmology, Temple University, 3401 N Broad Street, 6th Floor Parkinson Pavilion, Philadelphia, PA 19140, USA

${ }^{2}$ Department of Bioengineering, Temple University, 3401 N Broad Street, 6th Floor Parkinson Pavilion, Philadelphia, PA 19140, USA
} 